\title{
Evaluation of Primary Health Care attributes of Fortaleza city, Ceará State, Brazil
}

\author{
Avaliação dos atributos da Atenção Primária à Saúde de Fortaleza, Ceará, Brasil \\ Evaluación de los atributos de la Atención Primaria de Salud de Fortaleza, Ceará, Brasil
}

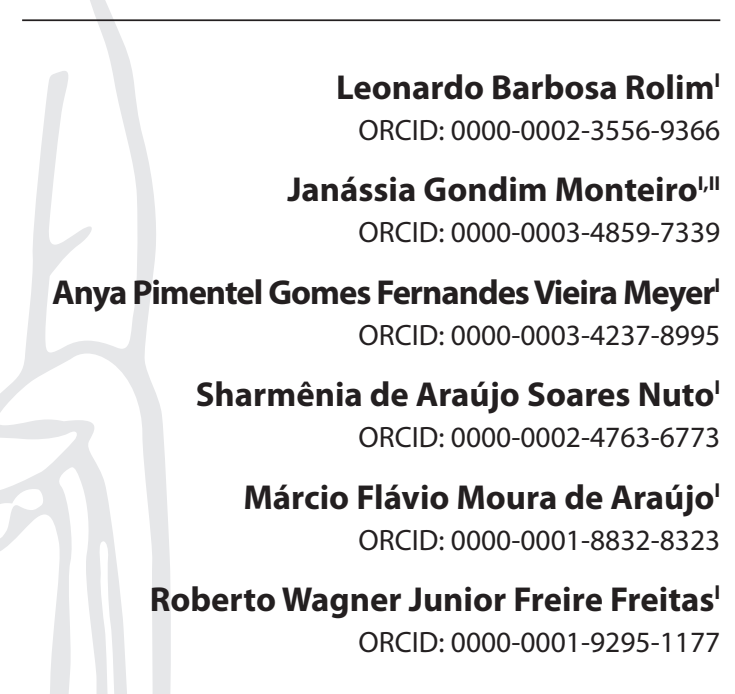

' Fundação Oswaldo Cruz Ceará. Fortaleza, Ceará, Brazil. "Universidade Federal do Ceará. Fortaleza, Ceará, Brazil.

How to cite this article:

Rolim LB, Monteiro JG, Meyer APGFV, Nuto SAS, Araújo MFM, Freitas RWJF. Evaluation of Primary Health Care attributes of Fortaleza city, Ceará State, Brazil. Rev Bras Enferm [Internet]. 2019;72(1):19-26. DOI: http://dx.doi.org/10.1590/0034-7167-2018-0033

Corresponding Author:

Roberto Wagner Júnior Freire Freitas

E-mail: robertowjff@gmail.com

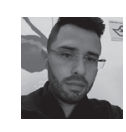

Submission: 02-25-2018

Approval: 06-08-2018

\section{ABSTRACT}

Objective: To evaluate the Primary Health Care attributes of Fortaleza city, Ceará State. Method: Evaluative study carried out at 97 Primary Health Care Units, from August 2015 to June 2016. 451 professionals from the Family Health Strategy participated in the study. We used the Primary Care Assessment Tool - Brazil, which evaluates the attributes, assigning scores on a scale of zero to ten. We adopted as a cut-off point, to consider high Primary Care score, attributes with a value of 6.60 or higher. Results: Among the eight attributes evaluated the First Contact Access and the Coordination Information System were the ones that obtained the lowest and highest scores, (2.98) and (7.82), respectively. The Overall Score, calculated by means of a mean of the attributes, was 6.34. Conclusion: The Primary Care evaluated had a low score, showing the need to discuss mechanisms to boost the attributes that obtained low scores. Descriptors: Primary Health Care; Health Services Research; Family Health Strategy; Health Evaluation; Public Health.

\section{RESUMO}

Objetivo: Avaliar os atributos da Atenção Primária à Saúde de Fortaleza, Ceará. Método: Estudo avaliativo realizado em 97 Unidades de Atenção Primária à Saúde, no período de agosto de 2015 a junho de 2016. Participaram da pesquisa 451 profissionais da Estratégia Saúde da Família. Foi utilizado o Primary Care Assessment Tool - Brasil, que avalia os atributos, atribuindo escores em uma escala de zero a dez. Adotaram-se como ponto de corte, para considerar escore alto da Atenção Primária, os atributos com valor igual ou superior a 6,60. Resultados: Dentre os oito atributos avaliados, o Acesso de primeiro contato e a Coordenação - sistema de informações, foram os que obtiveram menor e maior escore, $(2,98)$ e $(7,82)$, respectivamente. O Escore Geral, calculado através de uma média dos atributos, foi de 6,34. Conclusão: A Atenção Primária avaliada obteve baixo escore, demonstrando a necessidade de se discutir mecanismos para impulsionar os atributos que obtiveram escores baixos.

Descritores: Atenção Primária à Saúde; Pesquisa sobre Serviços de Saúde; Estratégia Saúde da Família; Avaliação em Saúde; Saúde Pública.

\section{RESUMEN}

Objetivo: Evaluar los atributos de la Atención Primaria d Salud de Fortaleza-CE. Método: Estudio evaluatorio realizado en 97 Unidades de Atención Primaria a la Salud, en el período de agosto de 2015 a junio de 2016. Participaron de la encuesta 451 profesionales de la Estrategia Salud de la Familia. Se utilizó el Primary Care Assessment Tool - Brasil, que evalúa los atributos, asignando escores en una escala de cero a diez. Se adoptaron como punto de corte, para considerar la puntuación alta de la Atención Primaria, los atributos con un valor igual o superior a 6,60. Resultados: Entre los ocho atributos evaluados, el Acceso de primer contacto y la Coordinación - sistema de informaciones, fueron los que obtuvieron menor y mayor puntaje $(2,98)$ y $(7,82)$, respectivamente. La Escala General, calculada a través de un promedio de los atributos, fue de 6,34. Conclusión: La Atención Primaria evaluada obtuvo bajo puntaje, demostrando la necesidad de discutir mecanismos para impulsar los atributos que obtuvieron escores bajos.

Descriptores: Atención Primaria de Salud; Investigación en Servicios de Salud; Estrategia Salud de la Familia; Evaluación en Salud; Salud Pública. 


\section{INTRODUCTION}

Primary Health Care (PHC) is defined as a set of values, principles and structuring elements (attributes) and should form the basis of national health systems as the best strategy to produce sustainable improvements and greater equity in health of the population. It is stated that a health service can be considered as a Primary Care Provider when it presents the four essential attributes (First Contact Access; Comprehensiveness and Coordination of (are). In addition, this same service can increase its power of interaction with individuals and the community by also presenting the derived attributes (family-centered health care, community guidance and cultural competence) ${ }^{(1)}$.

From this perspective, in the attempt to offer targeted services and PHC providers, the institutionalization of the Primary Care (PC) assessment culture in the Brazilian Unified Health System (SUS - Sistema Único de Saúde) has been fostered, since the evaluation of health services has been the central theme of public policies and considered an essential feature when it comes to service excellence.

In an attempt to improve the standard of quality of care at the Basic Health Units (BHU), the Ministry of Health $(\mathrm{MoH})$ has been presenting evaluation and monitoring tools for the $\mathrm{PC}$, among them the Primay Care Assessment Tool Brazil (PCATool) $)^{(1)}$. Created at the Johns Hopkins Primary Care Policy Center (PCPC), PCATool measures the presence and extent of essential attributes and attributes derived from $\mathrm{PHC}^{(2-3)}$.

Such a tool has its proven relevance, since due to the lack of tools to measure the set of interactions between users and health professionals; it fills the existing gap, while promoting individual baseline measurement on the structure and, mainly the process of care in PHC. In addition, it has been applied either nationally ${ }^{(4-5)}$ and/or internationally ${ }^{(2-3)}$.

It is worth noting that PCATool Brazil is adapted to the Brazilian reality. Each original version of the tool was transformed into an applicable tool through interviewers and underwent a process of translation and reverse translation, adaptation, debriefing, and content and construct validation, as well as reliability analysis ${ }^{(6-7)}$.

Some Brazilian studies have been carried out using the PCATool - Brazil tool in its three versions (adult users ${ }^{(8)}$, children caregivers $^{(8-9)}$ and health professionals $\left.{ }^{(10)}\right)$. However, when investigations are carried out in the Brazilian northeast, it is also noticed timidity in this production. Linked to this, there were no studies in the literature that evaluated the city of Fortaleza, Ceará State, using the version of PCATool for health professionals. It is worth mentioning that Ceará State has an intimate relationship with PHC, since it was the pioneer state to work with the care model focused on Family Health. Such facts were motivators for the design of the present study.

It is believed that studies of this nature, of an evaluative nature, offer subsidies for the improvement of PHC, insofar as they can enhance their attributes, whether essential or derived. We work with the perspective that we can invest in the development of intervention studies to soften and propose resolution of the main problems identified, as well as, in the perspective of enhancing the actions and attributes that are being developed in an appropriate way.
Thus, the study on screen had as objective to evaluate the presence and the extension of the PHC attributes in the city of Fortaleza, Ceará State.

\section{OBJECTIVE}

This study aims to evaluate the presence and extent of the Primary Health Care attributes in the city of Fortaleza, Ceará State.

\section{METHOD}

\section{Ethical aspects}

The study proposal was approved by the Research Ethics Committee of the University Hospital Walter Cantídio from the Universidade Federal do Ceará. All health professionals who accepted the invitation to participate in the study signed the Informed Consent Form. The fundamental ethical principles were prioritized at all stages of research, namely: Autonomy, beneficence, non-maleficence, justice and equity.

\section{Design, place of study and period}

This is an evaluative study, with a cross-sectional and quantitative approach, carried out in all 97 Primary Health Care Units (PHCU) of the city of Fortaleza, Brazil, between August 2015 and June 2016.

\section{Sample, criteria of inclusion and exclusion}

The study population was made up of health professionals (doctors, nurses and dentists) of both sexes, who make up the Family Health Strategy (FHS) teams, distributed in the six Regional Offices (RO) of Ceará capital. According to the Municipal Health Department, there were 1,083 higher education professionals in April 2015, distributed among 373 doctors, 423 nurses and 287 dentists. With the possession of the population number, we attempted to perform the sample calculation. For this, the formula for finite populations was used, using: $95 \%$ confidence interval, $50 \%$ prevalence and $4 \%$ sampling error. After the calculations due, the sample size resulted in 451 professionals.

It should be noted that the inclusion criteria were: To be a health professional and to be part of the FHS team in the city of Fortaleza, Ceará State, besides fulfilling a workload equal to or greater than 20 hours per week. Professionals who were on leave and/or vacations were excluded.

\section{Study protocol}

Data were collected from a three-part tool. The first one contained data for sociodemographic characterization (e.g.: Sex, age, marital status, religion), the second was composed of data related to academic training and professional experience (e.g.: Professional category, type of Higher Education Institution - HEI where Undergraduate Degree, Graduate Degree, Family Health training), and finally, in order to evaluate the presence and the extension of the attributes, the tool PCATool - Brazil, version for health professionals. 
The tool is composed of 77 items, divided into 8 components in relation to the $\mathrm{PHC}$ attributes:

1. First Contact Access - Accessibility (A). Composed of 9 items (A1, A2, A3, A4, A5, A6, A7, A8 and A9). They address whether the service is open on Saturdays and Sundays, open at least on certain days of the week until $8 \mathrm{pm}$, if it is easy for a user to be able to set a time for a health review appointment, among others.

2. Longitudinality (B). Composed of 13 items (B1, B2, B3, B4, B5, B6, $B 7, B 8, B 9, B 10, B 11, B 12$ and $B 13)$. The attribute has questions that address whether the health service is always attended by the same professionals, questions whether professionals can understand the questions that users ask if they feel comfortable with their patients' concerns and/or problems, among others.

3. Coordination-Care Integration (C). Composed of 6 items ( $C 1$, $\mathrm{C} 2, \mathrm{C} 3, \mathrm{C4}, \mathrm{C} 5$ and $\mathrm{C} 6$ ). In this attribute, professionals are asked if they are aware of the consultations their patients make to specialists, if someone from the health service helps the patient to make referrals, if the professional receives useful information about the referred patient, among others aspects.

4. Coordination - Information System (D). Composed of 3 items (D1, D2 and D3). Questions for this attribute include whether the health professional asks patients to bring their medical records received in the past, would allow patients to examine their charts if they wanted to and if the patient's charts are available when they are taken care of.

5. Comprehensiveness - Available Services (E). Composed of 22 items (E1, E2, E3, E4, E5, E6, E7. E8, E9, E10, E11, E12, E13, E14, E15, E16, E17, E18, E19, E20, E21 and E22). They are asked if the service offers a range of procedures, such as: Nutrition counseling, immunization, suturing of a cut, identification of hearing and visual problems, placement of splint, removal of warts and ingrown nails, among others.

6. Comprehensiveness-Services Provided (F). Composed of 15 items (F1, F2, F3, F4, F5, F6, F7, F8, F9, F10, F11, F12, F13, F14 and F15). It includes questions about the provision of different services such as: Advice on healthy eating, adequate sleep, home safety, seat belt counseling, ways to deal with family conflicts, how to prevent falls, prevention of osteoporosis in women, ways to deal with children's behavior problems, among others.

7. Family Guidance (G). Composed of 13 years (G1, G2 and G3), which addresses whether the health professional asks patients what their ideas and opinions are when planning treatment and health care if the practitioner asks about diseases and health problems that may occur in families and is willing and able to care for family members of patients to discuss a health problem or family problem.

8. Community Guidance $(H)$. Composed of 6 items $(\mathrm{H} 1, \mathrm{H} 2, \mathrm{H} 3$, $\mathrm{H} 4, \mathrm{H} 5$ and $\mathrm{H6}$ ). Here they are asked if they make home visits if they believe that the service has adequate knowledge of the health problems of the community they serve, if the health service hears opinions and ideas from the community to improve care, they do research with the patients to see if services are meeting (meeting) the needs of people, among others.

It is worth mentioning that for all the items asked, the following options were used: For sure, yes (Value $=4)$; Probably yes (Value $=3$ );
Probably not (Value $=2)$; Certainly not $($ Value $=1)$; I do not know/I do not remember (Value $=9$ ).

The scores for each of the attributes were calculated by the simple arithmetic mean of the item response values. Exceptionally, for the last item of the First Contact Access attribute (A9), there was a reversal of values. Item A9 corresponds to the following question: "On average, do patients have to wait more than 30 minutes to be attended by the doctor, nurse or dentist (not counting the triage or embracement)?". This item was formulated so that the higher the value (response) assigned, the lower the guidance for PHC. Therefore, this item had its value inverted for: (Value 4=1), (Value 3=2), (Value 2=3) and (Value 1=4).

To transform the scores into a scale of 0 to 10 , the following formula was used:

$\frac{(\text { Score obtained }-1) \times 10}{3}$

The Essential Score was measured by the sum of the mean score of the components that belong to the essential attributes, divided by the number of components:

$\frac{E S=(A+B+C+D+E+F)}{6}$

The General Score was measured by summing the mean score of the components belonging to the essential attributes and the components belonging to the derived attributes, divided by the total number of components:

$$
\frac{G S=(A+B+C+D+E+F)+(G+H)}{8}
$$

\section{Analysis of results and statistics}

The data was entered into Excel spreadsheets, Microsoft 2010 and later exported and analyzed using R Core Team Statistical Software, version 3.2.0 (2015). Initially, there was calculation of central tendency measures. In the analysis of the normality of the variables the Shapiro-Wilk test was adopted, obtaining a significant result for all the quantitative variables $(p<0.001)$, being chosen, therefore, the use of non-parametric tests for the accomplishment of the comparisons. In the association between sociodemographic and academic training variables with the professional category, the Chi-square test. On the other hand, we used the Kruskal-Wallis test to associate the mean scores of the PHC attributes with the professional category. We used as a cut-off point to consider a Primary Health Care high score, equal to or greater than 6.60, which equals, on a scale of 1 to 4 , a value of 3 (Probably yes). For all inferential procedures, we adopted a significance level of $5 \%(0.05)$.

\section{RESULTS}

451 FHS professionals from the city of Fortaleza, Ceará State participated, including 148 doctors, 189 nurses and 114 dentists. Age ranged from 23 to 65 years, mean of 39.5 ( $S D=9.0$ years). The female prevailed in the professional sample $(n=324,71.8 \%)$, the married or in stable relationship $(n=291,64.6 \%)$. Regarding religion, there were higher percentages for Catholics (69.8\%) and Evangelicals (12.9\%). 
In addition, $8.7 \%$ of professionals reported having no religion.

When questioned about the type of Higher Education Institution (HEI) where they finished their Undergraduate Degree, $68.1 \%$ stated that they had been in a public institution. The graduation year ranged from 1940 to 2015 , with a mean training time of 16 years ( $S D=9.6$ years). A significant portion of the sample had a Graduate Degree, 84.3\%. As for the type of Graduate Degree, the Specialization $(n=308)$ prevailed, followed by the Master's Degree ( $n=64)$, Residency $(\mathrm{n}=42)$ and $\mathrm{PhD}(\mathrm{n}=07)$.

By associating the sociodemographic and academic training variables with the professional categories, it was found that nurses and dentists were mostly female $(p<0.001)$. In turn, doctors were professionals who, proportionally, more stated that they did not have a religion ( $p<0.001$ ) and those who completed higher education in public HEI $(p<0.001)$

Regarding the Graduate Degree, dentists were the professionals who affirmed that they already had or were attending one $(p=0.030)$. However, dentists were the ones that proportionally fewer performed FHSrelated training in the last twelve months $(p<0.001)$ (Table 1).

Table 2 shows the distribution of the minimum, maximum, mean and Standard Deviation values for each of the PHC attributes evaluated in the city of Fortaleza, Ceará State, according to health professionals. In general, it is noticeable that the attributes, First Contact Accessibility and Coordination - Information System, were those that presented lower and higher mean score, 2.99 and 7.83, respectively.

As for the Essential Score (mean of the first six attributes), it was 6.06, while the General Score (mean of all eight attributes) was 6.35.

When we sought to associate the means of the PHC attributes scores with the professional category, it was noticed that the dentists were the ones who assigned the lowest scores to five attributes, demonstrating such association as statistically significant. The nurses assigned the lowest score for the Coordination - Care Integration attribute. In turn, doctors attributed lower scores to the Comprehensiveness - Available Services and Community Guidance attributes, but with no statistically significant association. Finally, there was a difference between the means of the "Essential" and "General" scores, according to the professional category $(p<0.001)$ (Table 3$)$.
Table 1 - Association between socio-demographic and academic training variables with the professional category, Fortaleza city, Ceará State, Brazil, 2016

\begin{tabular}{|c|c|c|c|c|c|c|c|c|c|}
\hline \multirow{3}{*}{ Variables } & \multicolumn{6}{|c|}{ Professional Category } & \multirow{3}{*}{$x^{2 *}$} & \multirow{3}{*}{$\mathbf{g}^{\mathbf{*}^{* *}}$} & \multirow{3}{*}{$\begin{array}{c}p \\
\text { value }\end{array}$} \\
\hline & \multicolumn{2}{|c|}{ Doctors } & \multicolumn{2}{|c|}{ Nurses } & \multicolumn{2}{|c|}{ Dentists } & & & \\
\hline & $\mathbf{n}$ & $\%$ & $\mathbf{n}$ & $\%$ & $\mathbf{n}$ & $\%$ & & & \\
\hline Sex & & & & & & & 72.17 & 2 & $<0.001$ \\
\hline Male & 74 & 50 & 16 & 8.4 & 37 & 32.5 & & & \\
\hline Female & 74 & 50 & 173 & 91.6 & 77 & 67.5 & & & \\
\hline Marital Status & & & & & & & 3.96 & 2 & 0.0138 \\
\hline Single/widow(er)/divorced & 62 & 41.9 & 61 & 32.3 & 37 & 32.5 & & & \\
\hline Married/Stable relationship & 86 & 58.1 & 128 & 67.7 & 77 & 67.5 & & & \\
\hline Presence of Religion & & & & & & & 16.00 & 2 & $<0.001$ \\
\hline Yes & 124 & 83.8 & 180 & 95.2 & 108 & 94.7 & & & \\
\hline No & 24 & 16.2 & 9 & 4.8 & 6 & 5.3 & & & \\
\hline HEI were finished graduation & & & & & & & 16.02 & 2 & $<0.001$ \\
\hline Public & 118 & 79.7 & 112 & 59.2 & 77 & 67.5 & & & \\
\hline Private & 30 & 20.3 & 77 & 40.8 & 37 & 32.5 & & & \\
\hline Graduate Degree & & & & & & & 7.02 & 2 & 0.030 \\
\hline Yes/in course & 109 & 86.5 & 165 & 93.7 & 106 & 96.3 & & & \\
\hline No & 17 & 13.5 & 11 & 6.3 & 4 & 3.7 & & & \\
\hline FHS training & & & & & & & 14.73 & 2 & $<0.001$ \\
\hline Yes & 120 & 81.1 & 125 & 66.1 & 69 & 60.5 & & & \\
\hline No & 28 & 18.9 & 64 & 33.9 & 45 & 39.5 & & & \\
\hline
\end{tabular}

Note: * Pearson's Chi-Square Test; ** Degrees of Freedom; *** Significance of the Pearson's Chi-Square Test; HEI - Higher Education Institution; FHS - Family Health Strategy.

Table 2 - Distribution of minimum, maximum, mean values and Standard Deviation of Primary Health Care attributes, Fortaleza city, Ceará State, Brazil, 2016

\begin{tabular}{lcccc}
\hline \multicolumn{1}{c}{ Attributes } & Minumun & Maximum & Mean & $\begin{array}{c}\text { Standard } \\
\text { Deviation }\end{array}$ \\
\hline First Contact Accessibility & 0.37 & 7.04 & 2.99 & 1.03 \\
Longitudinality & 2.82 & 9.49 & 6.05 & 1.23 \\
Coordination - Care Integration & 1.67 & 10.00 & 6.43 & 1.43 \\
Coordination - Information System & 0.00 & 10.00 & 7.83 & 1.81 \\
Comprehensiveness - Available Services & 2.27 & 9.39 & 6.32 & 1.13 \\
Comprehensiveness - Services Provided & 0.00 & 10.00 & 6.75 & 2.15 \\
Family Guidance & 0.00 & 10.00 & 7.67 & 2.01 \\
Community Guidance & 0.56 & 10.00 & 6.80 & 1.94 \\
Essential Score & 2.75 & 8.80 & 6.06 & 0.92 \\
General Score & 3.17 & 9.10 & 6.35 & 1.00 \\
\hline
\end{tabular}

Table 3 - Association between the means of Primary Health Care attributes scores and the Family Health Strategy professionals category, Fortaleza city, CearáState, 2016

\begin{tabular}{lcccc}
\hline \multicolumn{1}{c}{ PHC Attributes } & Doctors & Nurses & Dentists & p value* \\
\hline First Contact Accessibility & 3.01 & 3.10 & 2.78 & 0.014 \\
Longitudinality & 6.14 & 6.13 & 5.79 & 0.033 \\
Coordination - Care Integration & 6.61 & 6.13 & 6.68 & 0.001 \\
Coordination - Information System & 8.13 & 8.02 & 7.12 & $<\mathbf{0 . 0 0 1}$ \\
Comprehensiveness - Available Services & 6.24 & 6.28 & 6.51 & 0.284 \\
Comprehensiveness - Services Provided & 7.64 & 7.54 & 4.26 & $<\mathbf{0 . 0 0 1}$ \\
Family Guidance & 8.22 & 7.73 & 6.85 & $<\mathbf{0 . 0 0 1}$ \\
Community Guidance & 6.71 & 6.87 & 6.80 & 0.582 \\
Essential Score & 6.29 & 6.20 & 5.51 & $<\mathbf{0 . 0 0 1}$ \\
General Score & 6.59 & 6.47 & 5.84 & $<\mathbf{0 . 0 0 1}$ \\
\hline
\end{tabular}

Note: * Significance of the Kruskal-Wallis Test; Primary Health Care-PHC. 


\section{DISCUSSION}

As previously seen, eight attributes were evaluated in the present study, with First Contact Accessibility being the attribute with the lowest mean score (2.99). Besides, the Essential Score - ES (mean of the first 6 attributes) and the General Score - GS (mean of all 8 attributes) were 6.06 and 6.35 , respectively, that is, both did not reach values higher than the point which means that they were classified as low PHC scores, a fact that is worrying for the city of Fortaleza, Ceará State, demonstrating that there is still a lot to improve in the quality of these services, in order to guarantee not only the presence but also the a broad extension of the PHC attributes.

The Essential Score (ES) and the General Score (GS) of the present study were lower than those of other investigations carried out in Brazil, specifically in Minas Gerais (ES: 7.12 and GS: 7.40)(11), Rio Grande do Sul (ES: 6.84 and GS: 7.08) ${ }^{(12)}$, Paraná (ES: 7.10 and GS: 7.4)(13), Santa Catarina (ES: 6.80 and GS: 7.09)(14) and Federal District (ES: 6.46 and GS: 6.62) States ${ }^{(15)}$.

We know the complexity and the great challenge of evaluating health services. The Brazilian Ministry of Health itself has been presenting constant evaluation initiatives in the Brazilian Unified Health System and, consequently, in the Family Health Strategy. The Programa Nacional de Melhoria do Acesso e da Qualidade da Atenção Básica (PMAQ-AB - National Program for Improving Access and Quality of Primary Care), for example, in 2017 (in its third cycle), had its external evaluation carried out in several Brazilian states. We cannot forget that several aspects are interwoven in the interpretation of the evaluation processes, being: Economic, social, cultural, among others. The Ceará State, despite being a pioneer in important Primary Care programs (such as the Community Health Agents and the FHS itself), has shown low scores in its attributes, denoting, according to health professionals, that the FHS capital is not a provider of PHC. This finding is worrying, demonstrating the real need to discuss such results. What are the real reasons why professionals are assigning such low scores?

For example, the results of this survey for First Contact Accessibility have shown a mean score of 2.99 , setting it low. Before interpreting the number itself, it is necessary to understand the essence of the attribute. Accessibility is the attribute that places $\mathrm{PHC}$ as the gateway to the health system. It means access to and use of the health service for each new health event or new episode of the same event, being the first resource to be sought when there is a need/health problem ${ }^{(16-17)}$. A health service that is not accessible hurts one of SUS's fundamental principles, universality. However, Fortaleza has not been the only place in Brazil where this evaluation has been negative. Searches in the literature state that in Chapecó, Santa Catarina, the score was 3.6 $6^{(14)}$. Another research, this time performed in seven municipalities in Goiás State, has found a score of $2.42^{(18)}$.

It is also important to evaluate the items that make up this attribute. Although the tool has been validated in Brazil, some questions do not depict the Brazilian reality. For example, for the vast majority of Basic Health Units, it is not recommended that they be open on Saturdays and Sundays, just as it is not recommended to use the telephone for patient guidance. Even so, these questions remain part of the evaluation tool, which ultimately influences negative outcomes. Thus, the need to revisit PCATool is notorious, in order to discuss which items, in fact, are valid to remain in the tool. The context in which the tool was initially constructed differs substantially from the Brazilian context. In addition, Brazil, because it has continental dimensions, needs a broad discussion to validate the tool according to the characteristics of its regions, especially with regard to access, since there are extremely densely populated areas as well as the difficult geographical access, as the Northern cities of the country.

In view of the above, it is reiterated that the attribute First Contact Accessibility was evaluated by health professionals as unsatisfactory at Fortaleza's FHS. This fact should be discussed among the actors in this process, serving as the basis for possible changes. In order for the FHS to become a "gateway", it is necessary for its services to be accessible and used for every new need or health problem.

Regarding the Longitudinality attribute, the present study revealed a low mean score (6.05). This result differs from those found in some studies ${ }^{(11-19)}$, which presented higher mean scores. However, in another Brazilian study, the score obtained for the attribute was lower than ours, $6.0^{(14)}$. It should be noted that Longitudinality is associated with greater familiarity with the patient, better identification of health problems and patient satisfaction, that is, items of great importance for the context of the Family Health Strategy and, consequently, PHC. When evaluating the items that make up the attribute, it was noticed that the worst results were associated with the questions: If the patients have a question, can they call and talk to the doctor or nurse who knows them better?; Do you know who lives with each of your patients?; and Do you know the job or work of each patient?

In fact, as stated earlier, Primary Health Care in Brazil, as well as in the Northeast, does not routinely use telephone services to contact the service and receive assistance through this means. In addition, the high turnover of healthcare professionals weakens the bond and the logitudinality of care. Such data make us reflect on the real need to rethink such practices and promote scenarios that may modify this reality.

On the other hand, the Coordination - Care Integration attribute, in this study, obtained a score of 6.43. This finding differs from two studies found in the literature ${ }^{(11-13)}$, which found higher scores, 6.91 and 7.0, respectively. The attribute, in itself, is of great importance and is anchored in different aspects. For example, as regards referrals and counterreferrals, there was a certain weakness in the coordination process, since the communication occurs unidirectionally, since the majority of FHS professionals revealed that they had not received from the specialized service the information about the referred patient. Such a statement was similarly found in the study conducted in Piracicaba in the year 2014, reinforcing significant differences between the transfer of information ${ }^{(20)}$. This should not be routine in PHC services. The user referred to a specialized service needs to have, minimally, the flow of information. Once this flow is broken, care and care rendered fragile, disintegrating the actions implemented until then.

The Coordination - Information System attribute obtained a high mean score, 7.83 , on a scale of zero to ten. This finding is also evidenced in other studies that used PCATool - Brazil, professional version $^{(12-13,15)}$. In this context, an important tool that contributes 
to obtaining an effective health information in PC is the medical record. In the studied reality, it is noticed that the majority of professionals refer to the availability of medical records at the moment of service ${ }^{(21)}$. In the scope of the FHS, especially for what is proposed, the medical record assumes a differentiated configuration and begins to have a connotation of family history.

The mean score obtained from the Comprehensiveness - Available Services attribute was 6.32. The use of the FHS to obtain the range of available preventive services has been evaluated to a satisfactory degree, in accordance with the Política Nacional da Atenção Básica (freely translated as National Policy on Primary Care), which indicates that the FHS should be focused on the promotion and protection of health. However, the negative evaluation attributed to the items (Suture of a cut that needs stitches, Placement of splint, Removal of warts and Removal of ingrown nail), performed the mean score low. These findings are useful for the actors involved in the process (professionals, managers and users) to rethink what services should really be offered in Primary Care and which ones should be available in the Rede de Atenção à Saúde (Health Care Network).

Regarding the Comprehensiveness - Services Provided attribute, the mean score obtained was 6.75. For all three questions, negative responses were meaningful: Do you discuss with your patients about possible exposures to hazardous substances in the home, at work, or in the neighborhood?; Do you ask if the patient has a firearm and guides how to safely store it ?; Do you discuss how to prevent burns caused by hot water, hot oil? It is possible that Fortaleza's FHS professionals are not performing basic and necessary services to the population.

Faced with such findings, it is important to discuss what services should actually remain and what should be included in the $\mathrm{PHC}$, since it is relevant to raise local demands and to know all the logistics of the Rede de Atenção à Saúde (Health Care Network). What should not be prioritized is only the fulfillment of specific programs, restricted to groups, leaving aside services that are important and necessary to registered users.

For Family Guidance, the mean score was 7.67, considered a high value, demonstrating that the Fortaleza FHS services have a strong PHC guidance, according to this attribute. In this context, there is a strong interest of health professionals of the FHS de Fortaleza regarding the life conditions of users and their relatives, being characterized, for example, by the existence of issues about social risk factors and presence of discussions with other family members about the health problems found.

The results of the present study showed a high score for the Community Guidance attribute (6.80), demonstrating that the attribute in question is more present in health services working in the FHS model when compared to traditional $\mathrm{PHC}$ services ${ }^{(18,20)}$.

The mean scores of the "First Contact Accessibility" $(p=0.014)$, "Longitudinality" ( $p=0.033)$, "Coordination - Information System" ( $p<0.001$ ), "Comprehensiveness - Services Provided", "Family Guidance" ( $p<0.001)$ attributes were significantly lower in the perception of dentists.

This evaluation has important implications for PHC guidance, since the lack of knowledge or approximation of the health problems of the population and services by this professional class is evident, which presents itself as a challenge to be overcome by establishing a relationship of proximity and knowledge of the demands of services, since the production of health requires the establishment of relationships and intersubjectivities between professionals and users, opening the possibility of approach to the world of patients lives and, therefore, to their world of becoming sick.

The nurses assigned the lowest score for the "Coordination - Care Integration" attribute ( $p<0.001)$. Discussions and problems related to the coordination of health care, fragmentation of care network, lack of communication between providers, are not new topics in the discussions on the organization of health systems. However, recent changes in the demands and needs of the population with the increase in the prevalence of chronic diseases, which require greater contact with the health services in a context of pressure for optimization of cost-efficiency relations, have made the search for solutions ${ }^{(22)}$.

Brazilian scholars point out the heterogeneity of the quality of care provided by the FHS teams, as well as the challenges of expanding their capacity to respond to new and old health problems that affect health in the country ${ }^{(8)}$. However, studies of this nature, which seek to hear and include health professionals in the process of evaluating health services, are important, since it means having the look of who is in the service or of a program and who exercises the management of care, experiencing the realities and difficulties of the health services and the territory ${ }^{(5)}$.

\section{Study limitations}

Some limitations can be highlighted, such as the fact that the data collection was performed at only one point of time, which characterizes the cross-sectional outlining studies. In addition, only three professional categories were surveyed (doctors, nurses and dentists). In addition, it is known that there are three versions of the PCATool. For the present research, the professional version was used. It is believed that further investigations can be carried out using the versions for adult users and children caregivers.

\section{Contributions to the sectors of Nursing, Health or Public Policy}

It is of the utmost importance that these results be discussed among health and management professionals in an attempt to search for mechanisms that can enhance the attributes that were well evaluated and to boost those who obtained low scores. In addition, listening to professional categories is a prime task, since this assessment was performed from their perspective. Understanding the nuances of each profession within the FHS may be a good strategy to try to address the disparities found between the categories during assessment.

\section{CONCLUSION}

The Essential and General Scores of the study on screen allowed us concluding that the FHS of Fortaleza presents a low PHC score, since it did not reach the cut-off point of 6.60 adopted by the Ministry of Health of Brazil.

Eight attributes of the PHC were evaluated, with "First Contact Access" being the attribute with the lowest score (2.99) and the "Coordination - Information System" with the highest score (7.83). 
The scores of the "First Contact Access", "Longitudinality", "Coordination - Information System", "Comprehensiveness - Services Provided" and "Family Guidance" attributes were significantly lower in the perception of dental professionals. The nurses were the professionals who assigned a lower score for the "Coordination - Care Integration" attribute and the doctors who assigned lower scores for the "Comprehensiveness - Available Services" and "Community Guidance" attributes.

\section{REFERENCES}

1. Ministério da Saúde (BR), Secretaria de Atenção em Saúde, Departamento de Atenção Básica. Manual do instrumento de avaliação da atenção primária à saúde: primary care assessment tool pcatool - Brasil [Internet]. Brasília: Ministério da Saúde; 2010 [cited 2018 Feb 18]. 80p. Available from: http://bvsms.saude.gov.br/bvs/publicacoes/manual_avaliacao_pcatool_brasil.pdf

2. Cassady CE, Starfield B, Hurtado MP, Berk RA, Nanda JP, Friedenberg LA. Measuring consumer experiences with primary care. Pediatrics [Internet]. 2000 [cited 2018 Feb 18];105(4 Pt 2):998-1003. Available from: https://www.ncbi.nlm.nih.gov/pubmed/10742362

3. Shi L, Starfield B, Xu J. Validating the Adult Primary Care Assessment Tool. J Fam Prac [Internet]. 2001 [cited 2018 Feb 18];50(2):161-75. Available from: https://www.mdedge.com/jfponline/article/60464/validating-adult-primary-care-assessment-tool

4. Oliveira MPR, Menezes IHCF, Sousa LM, Peixoto MRG. [Training and Qualification of Health Professionals: Factors associated to the Quality of Primary Care]. Rev Bras Edu Méd [Internet]. 2016 [cited 2018 Feb 18]; 40(4):547-59. Available from: http://dx.doi.org/10.1590/198152712015v40n4e02492014 Portuguese.

5. Lima EFA, Sousa Al, Leite FMC, Lima RCD, Souza MHN, Primo CC. Evaluation of the Family Healthcare Strategy from the Perspective of Health Professionals. Esc Anna Nery [Internet]. 2016 [cited 2018 Feb 18]; 20(2):275-80. Available from: http://dx.doi. org/10.5935/1414-8145.20160037

6. Harzheim E, Starfield B, Rajmil L, Dardet CA, Stein AT. [Internal consistency and reliability of Primary Care Assessment Tool (PCATool-Brasil) for child health services]. Cad Saúde Pública [Internet]. 2006 [cited 2018 Feb 18]; 22(8):1649-59. Available from: http://dx.doi.org/10.1590/ S0102-311X2006000800013 Portuguese.

7. Harzheim E, Duncan BB, Stein AT, Cunha CRH, Gonçalves MR, Trindade TG, et al. Quality and effectiveness of different approaches to primary care delivery in Brazil. BMC Health Serv Res [Internet]. 2006 [cited 2018 Feb 18];6:156. Available from: https://www.ncbi.nlm.nih.gov/pmc/ articles/PMC1790713/

8. Harzheim E, Pinto LF, Hauser L, Soranz D. Assessment of child and adult users of the degree of orientation of Primary Healthcare in the city of Rio de Janeiro, Brazil. Ciênc Saúde Colet [Internet]. 2016 [cited 2018 Feb 18];21(5):1399-408. Available from: http://dx.doi. org/10.1590/1413-81232015215.26672015

9. Silva CB, Paula CC, Lopes LFD, Harzheim E, Magnago TSBS, Schimith MD. Health care for children and adolescentes with HIV: a comparison of services. Rev Bras Enferm [Internet]. 2016 [cited 2018 Feb 18]; 69(3):489-97. Available from: http://dx.doi. org/10.1590/0034-7167.2016690315i

10. Ferreira VD, Oliveira JM, Maia MAC, Santos JS, Andrade RD, Machado GAB. Assessment of Primary Healthcare atributes in one Municipality of Minas Gerais State. Esc Anna Nery [Internet]. 2016 [cited 2018 Feb 18];20(4):e20160104. Available from: http://dx.doi. org/10.5935/1414-8145.20160104

11. Silva AS, Nogueira DA, Paraizo CMS, Fracolli LA. Assessment of primary health care: health professionals perspective. Rev Esc Enferm USP [Internet]. 2014 [cited 2018 Feb 18]; 48(Esp):122-8. Available from: http://dx.doi.org/10.1590/S0080-623420140000600018

12. Castro RCL, Knauth DR, Harzheim E, Hauser L, Duncan BB. Quality assessment of primary care by health professionals: a comparision of diferente types of services. Cad Saúde Pública [Internet]. 2012 [cited 2018 Feb 18];28(9):1772-84. Available from: http://dx.doi.org/10.1590/ S0102-311X2012000900015 [Portuguese]

13. Chomatas E, Vigo A, Marty I, Hauser L, Harzheim E. Evaluation of the presence and extension of the atributes of primary care in Curitiba. Rev Bras Med Fam Comunidade [Internet]. 2013 [cited 2018 Feb 18]; 8(29): 294-303. Available from: http://dx.doi.org/10.5712/rbmfc8(29)828 [Portuguese]

14. Vitoria AM, Harzheim E, Takeda SP, Hauser L. [Evaluation of primary health care atributes in Chapecó, Brazil]. Rev Bras Med Fam Comunidade [Internet]. 2013 [cited 2018 Feb 18]; 8(29):285-93. Available from: http://dx.doi.org/10.5712/rbmfc8(29)832 Portuguese.

15. Araujo RL, Mendonça AVM, Sousa MF. Perception of users and health professionals in the Federal District: the atributes of primary care. Saúde Debate [Internet]. 2015 [cited 2018 Feb 18]; 39(105):387-99. Avaliable from: http://dx.doi.org/10.1590/0103-110420151050002007

16. Ministério da Saúde (BR), Secretaria de Gestão do Trabalho e da Educação na saúde, Universidade Aberta do Sistema Único de Saúde. Competências dos profissionais de nível superior na estratégia de saúde da família [Internet]. Brasília: UNA-SUS, 2011 [cited 2018 Feb 18 ]; 88 p. Available from: https://ares.unasus.gov.br/acervo/handle/ARES/10267

17. Reis RS, Coimbra LC, Silva AAM, Santos AM, Alves MTSSB, Lamy ZC, et al. [Access to and use of the services of the family health strategy from the perspective of managers, professionals and users]. Ciência Saúde Colet [Internet]. 2013 [cited 2018 Feb 18];18(11):3321-31. Available from: http://dx.doi.org/10.1590/S1413-81232013001100022 Portuguese.

18. Van Stralen CJ, Belisário AS, Van Stralen TBS, Lima AMD, Massote AW, Oliveira CL. [Perceptions of primary health care among users and 
health professionals: a comparison of units with and without family health care in Central-West Brazil]. Cad Saúde Pública [Internet]. 2008 [cited 2018 Feb 18]; 24(Sup1):S148-58. Available from: http://dx.doi.org/10.1590/S0102-311X2008001300019 Portuguese.

19. Elias PE, Ferreira CW, Alves MCG, Cohn A, Kishima V, Escrivão JA, et al. [Primary Health Care: a comparison of PSF and UBS units per stratum of socially excluded users in the city of São Paulo]. Ciência Saúde Colet [Internet]. 2006 [cited 2018 Feb 18];11(3):633-41. Available from: http://dx.doi.org/10.1590/S1413-81232006000300012 Portuguese.

20. Cesar MC, Campos GWS, Montebelo MIL, Sarmento G. [Assement of Primary Health Care in the municipality of Piracicaba, SP, Brazil]. Saúde Debate [Internet]. 2014 [cited 2018 Feb 18]; 38(especial):296-306. Avaliable from: http://dx.doi.org/10.5935/0103-1104.2014S022 Portuguese.

21. Carneiro MSM, Melo DMS, Gomes JM, Pinto FJM, Silva MGC. [Assessment of the coordination atribute in Primary Health Care: application of the PCATool to professionals and users]. Saúde Debate [Internet]. 2014 [cited 2018 Feb 18];38(especial):279-95. Available from: http://dx.doi. org/10.5935/0103-1104.2014S021 Portuguese.

22. Almeida PF, Giovanella L, Mendonça MHM, Escorel S. [Challenges for healthcare coordination: strategies for integrating levels of care in large cities]. Cad Saúde Pública [Internet]. 2010 [cited 2018 Feb 18]; 26(2):286-98. Avaliable from: http://dx.doi.org/10.1590/S0102311 X2010000200008 Portuguese. 